\title{
RESEARCH OF LABOR MARKET POLICIES IN BULGARIA
}

\author{
S. Raychev \\ Department of Economics, Faculty of Economic and Social Sciences, Plovdiv University \\ "Paisii Hilendarski", Plovdiv, Bulgaria
}

\begin{abstract}
This article analyzes the labor market policies in Bulgaria. Using labor market indicators, the article aims to measure policies efficiency. Using the method of comparison, between labor market policies in Bulgaria and the other EU member countries, the article reveals the negative condition of public labor expenditures and labor market efficiency.
\end{abstract}

Key words: unemployed, labor market policy, activation, public expenditures

\section{INTRODUCTION}

The problems facing all economic and social policies are related to the effective use of nation-al human resources. The effectiveness of the labor market is key to the effective functioning of other markets. Therefore subjects of the labor market - supply and demand workforce are subject to intervention by the state. One of the main instruments for intervention by the state is public policies on the labor market. Their goal is to achieve full and effective use of the active population. This is done by specifying groups on un-employed long-term unemployed, inactive youth unemployment and inactivity, etc. Through various initiatives, public policies of the labor market aimed at reducing unemployment, particularly long-term unemployment, reducing the inactive population, with priority focus on youth as intellectual potential of the state. After the global crisis of 2008 in Bulgaria, as in other EU countries show imbalances and inefficient operating at the labor market. Rising unemployment, poverty, the risks of social exclusion and inactivity caused by a sense of hopelessness created the need for strengthening state intervention in regulating market processes. Thus in Bulgaria and other EU countries strengthen interest in public policies on the labor market. This is expressed both in the theoretical justification of the need for them and their character differentiation mechanism and tools, and enhanced their empirical application expressed in raising the cost of this type of poli-cies. The purpose to this article is to explore public policies on the labor market in Bulgaria. Their role and effectiveness compared to their operations in other EU countries. Analyzing the role of public policy is aggregated and displayed their condition and makes a proposal for effective regulation of the labor market through this type of instrument.

\section{THEORETICAL REVIEW}

Public policies on the labor market are an essential tool for regulating the labor market. The European Union methodology (1) summarizes theoretical structure of public policies on the labor market. The essence of public policies on the labor market is that it is a tool of economic and social state policy. Focusing on labor market policies in the labor market aimed at achieving the effective functioning of the labor market through the correction of imbalances in the market. They differ from other instruments aimed at efficient and potentially functioning of the labor market by focusing on particular individuals or groups for intervention. EU classifies economic policies generally accepted understanding of the classification adopted in the economictechnical environments. According to the methodology adopted, the EU recognizes three types of intervention in the labor market:

- Services - this type of intervention covers the mechanisms of coordination between the subjects of the labor market. This translates into information and technical assistance on supply and demand of labor between the subjects of the labor market;

- Measures - this type of intervention focuses on changing the employment status of the 
beneficiary and includes direct measures such as the activation of unemployed or assist disadvantaged groups, etc;

- Support - this type of intervention included financial support to individuals or groups due to drain the circumstances are disadvantaged or are forced to exit early from the labor market;

Policies on the labor market focus on three main groups: the unemployed, employed at risk and inactive. Within three types of interventions, the EU recognizes the following classification of types of interventions:

1. Services of the labor market - carried out by certain public agencies or authorities and aimed at promoting integrity among employers' preferences and the preferences of individuals seeking employment;

2. Training - public funding of various types of training and qualification in order to improve the employability of individuals;

3. Incentives for employment - financial measures to increase recruitment of unemployed persons or groups subject to intervention by the policies of the labor market;

4. Stimulate employment and rehabilitation measures and financial incentives to promote employment of persons with low disability, disabled or persons with disabilities;

5. Direct job creation - job creation in the public sector for long-term unemployed individuals or those with which no perspective for taking another job;

6. Encourage entrepreneurship - measures designed to encourage individuals to start their own business or just insurance;

7. Income support for unemployed individuals - including measures aimed at improving the income of persons seeking employment but unemployed at the time as unemployment benefits, etc.

8. Early retirement - measures supporting partial or complete retirement of individuals who are very hard to find work in the years be-fore retirement;

These interventions cover the tools of public policies on the labor market aimed at improving efficiency in the labor market.

\section{METHODOLOGY}

The study of public policies in Bulgaria will be made through the following analyzes:

- Analyze the costs of public policies on the labor market in Bulgaria and other EU Member States;
- Analyzing the trend of the cost of public policies on the labor market for the period 2005 - 2012.

- Study the effectiveness of policies on the labor market through indicators for incorporation and activation of the unemployed.

Putting the state and trends of public policies in Bulgaria along with their effective functioning allows for the presentation of the problems associated with state intervention in the labor market.

\section{RESULTS}

The survey data for the cost of public policies on the labor market in Bulgaria and other EU Member States are represented in Figure 1. The data show that spending on public policies in Bulgaria, taking into costs for all types of interventions (LMP 1- 9) compared to other EU countries are very low. As the graph shows Bulgaria pays $0.694 \%$ of GDP for public policies on the labor market. Only seven countries spend a smaller percentage of GDP for the policies of the labor market. The average rate for the EU Member States amounted to 1,891 as part of GDP. The difference between the average rate for Europe and for Bulgaria the percentage is almost three times. The costs of public policies on the labor market in Bulgaria are more than 5 times lower than the highest values for the EU. The conclusion that can be drawn from these data is that in Bulgaria the problems of the labor market ignored or at least neglected policies on the labor market as a tool for increasing the efficiency of the market mechanism.

Important information gives us the data presented in Figure 2, which show the trends in the cost of policies on the labor market in Bulgaria and the EU average for the period of 7 years. The figure clearly displayed linear trend line showing the change in values. The change in the average of the EU is almost negligible. This evidenced by the trend line, which is almost horizontal - the change from the first to the last year, a decrease of $7 \%$. Such as $7 \%$ change in GDP percentage that average EU pays for public labor market politics. On the other hand is displayed trend line change cost for public policies on the labor market in Bulgaria also log amendment. The cost trend line of Bulgaria clearly shows a sharp reduction in their value as a percentage of GDP. Compared to the 7 - percent difference for the EU in Bulgaria the percentage change between the first and last year - respectively 2005 and 2012 more than 50\%. These trends present a disturbing picture. After the onset of 
RAYCHEV S.

the global crisis of 2008 followed negative trends in the economies of the EU member states, one of which is acute unemployment. As a step towards limiting and restoring the functioning of the labor market, most Member States increased their spending policies for the labor market. This is clearly shown by the fact that the percentage of GDP spending on average in the EU in the period 2009 - 2012 is
- higher than the rate in 2007 - 2008, before the crisis. Opposite data shows Bulgaria. The amount of funds allocated for the policies of the labor market in Bulgaria, despite its growth in the post-crisis period 2009 - 2012 is about double than the amount of expenditure before it - the period 2006 - 2008, this is surprising considering market data Labour in the postcrisis period.

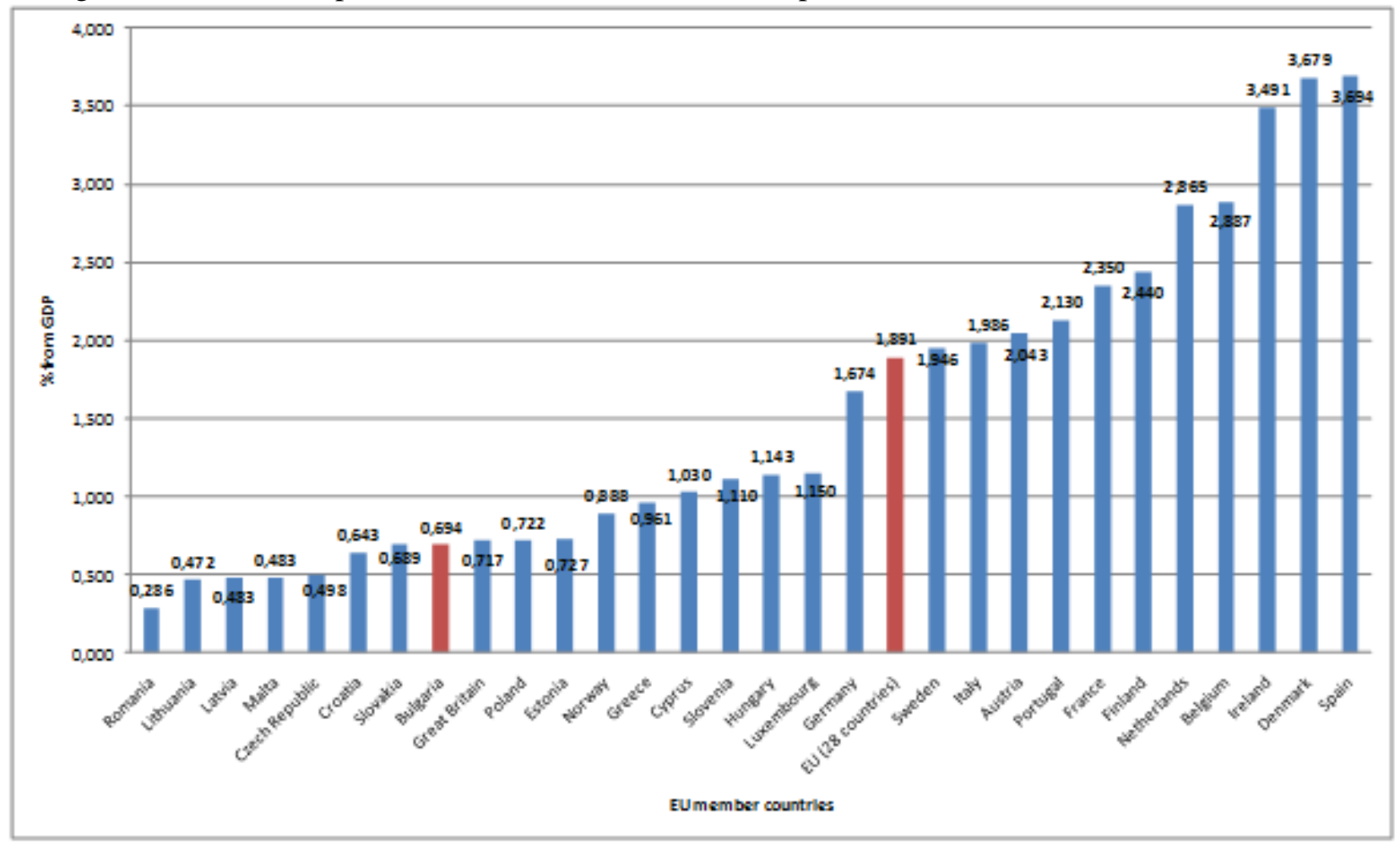

Figure 1. Public expenditure on labor market policies as \% of GDP in 2012.

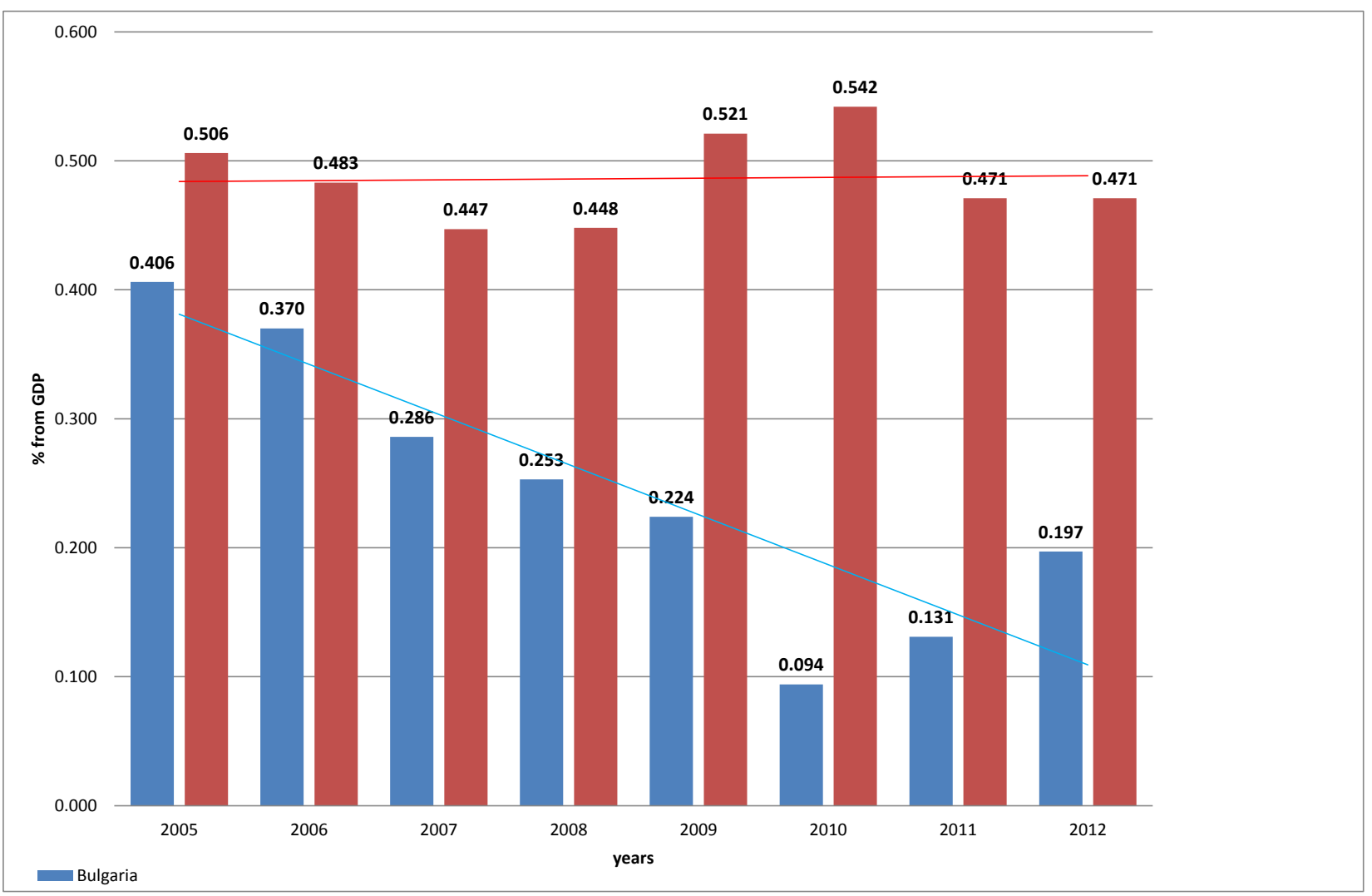

Figure 2. Public expenditure on labor market policies as \% of GDP in Bulgaria and EU 
One of the key indicators representing the functioning of the labor market is unemployment. If you examine the data for Bulgaria and the EU average shows that if in 2008 the unemployment rate in Bulgaria was $5.6 \%$ and $7 \%$ in the EU, then the next year the situation reversed. In 2010, unemployment, respectively - $10.3 \%$ for Bulgaria, 9.6\% for the EU; 2011 unemployment in Bulgaria - 11.3\%, the EU - 9.6; 2012 figures are for Bulgaria $12.3 \%$ and the EU - 10.4\%; in 2013 Bulgaria $13 \%$, the EU $-10.8 \%$. These data were to show that even low levels of unemployment before the crisis in Bulgaria after its occurrence, the situation reversed. And the change in the period 2010 - 2013 is upward, the difference being-gating increases more and more. Another important indicator of the labor market is inactive population. This indicator also reflects one of the target groups of the policies of the labor market - persons outside the labor force. The values for Bulgaria and the EU are similar to those for unemployment. Policies on the labor market perceived inactivity as one of the groups subject to intervention. But in particular those policies focusing on the young part of this group - persons 29 years confronting their entire working life. Data on the inactive population for 2013 of between 15 and 74 years are as follows: $40.1 \%$ for Bulgaria to EU average $36 \%$. With a higher value than those of Bulgaria are only five countries that have values of the inactive population to $4 \%$ higher than those of Bulgaria. At low values for this indicator in the EU are $28.5 \%$. But sharp are inactive data-Community young individuals leaving the education system. This indicator inactive persons aged between 25 and 29 years, Bulgaria is second. The figures for 2013 are as follows: Bulgaria - 25.6\%, the EU - 17.6\%. Only Italy has a higher value than Bulgaria $32.2 \%$. These inactive population shows that this indicator of the labor market in Bulgaria is experiencing in - big problems from those of other EU countries. In summary it can be concluded that the magnitude of the problems of the labor market in Bulgaria does not correspond to the size of public policies on the labor market expressed as funds allocated to them. Moreover, in the years after the crisis deepening problems go hand in hand with reducing funds available for policies in the labor market.

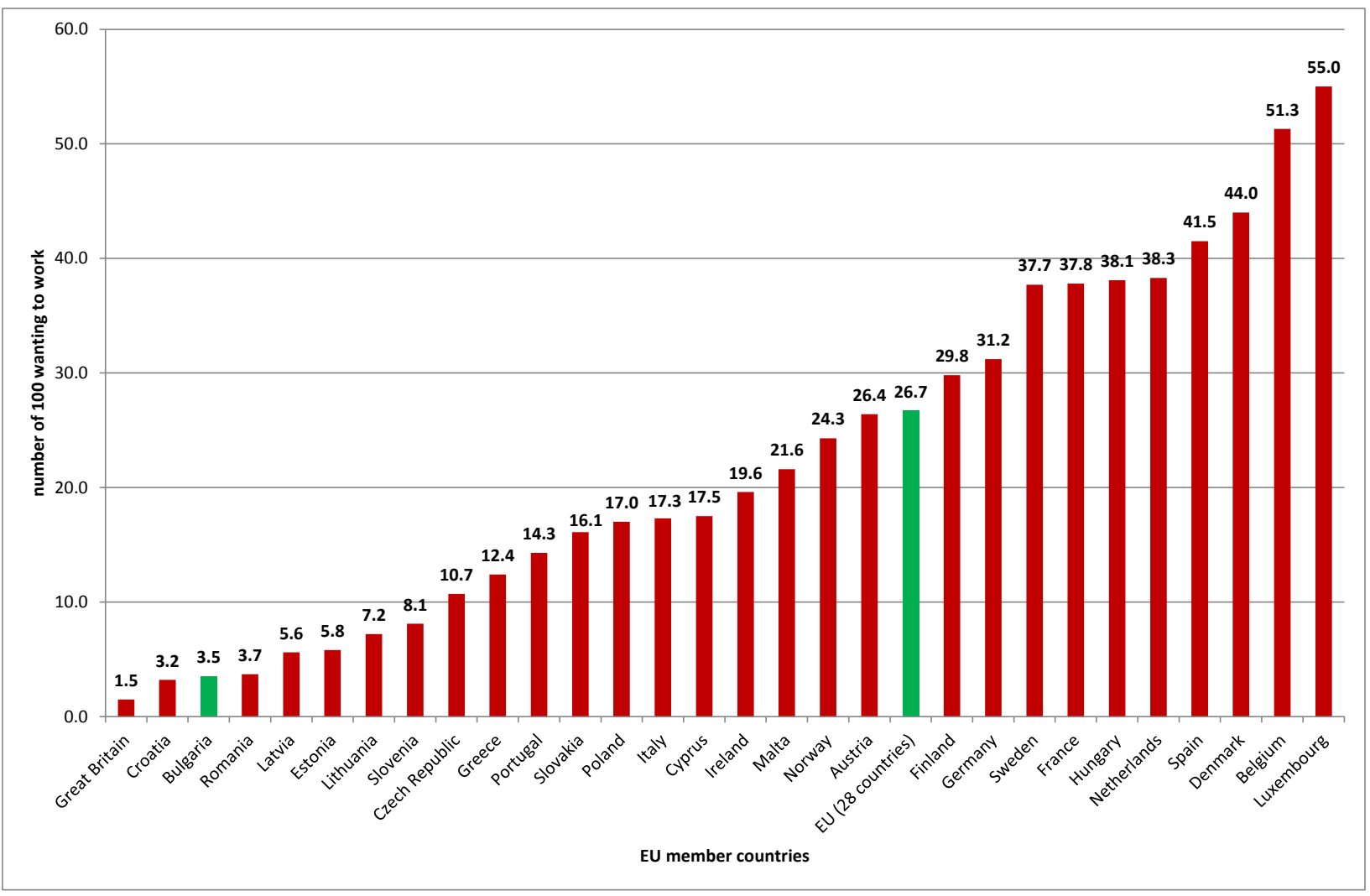

Figure 3. LMP participants per 100 persons wanting to work

High rates of unemployment and inactivity in the population can be explained by the low cost of prevention in the form of policies on the labor market and as a reason for their increase. But how effective is an economic and social policy of the labor market depends not only on the correlation between the amount of the costs for the prevention and imbalances in 
RAYCHEV S.

the labor market. Another important point is how policy works in the labor market, regardless of their volume function effectively. In Figure 3 you can see the data for one of the indicators showing the effectiveness of policies on the labor market. The data show "Activation and support" policies on the labor market in the form of number of participants in their various instruments to 100 individuals want to work. Data are for 2012 and cover only active policies on the labor market. These are tools (2-7) Eurostat classification and have been taken because of their active role in changing the status of individuals. The high participation in the programs of the policies of the labor market is a guarantee for their role in the interventions of their labor market. As seen in Figure 3, the value for Bulgaria is 3.5 people involved in the TPA to the average rate for EU countries - 26.7\%. The huge difference is reinforced by figures in leading European economies and perceived social economic model - Germany, France, Denmark, Sweden,
Belgium, and the Netherlands. Their values of 30 , reach more than 50 people involved in the TPA at 100 jobseekers. This indicator is indicative of the efficiency of public policies in the labor market as a tool for intervention on the imbalances in the labor market and more specifically on unemployment, inactivity, etc. Furthermore indicator part of the unemployed in public policy measures on the labor market, another important indicator of their efficacy indicator "Activation of registered unemployed." This indicator is displayed as a factor activating the unemployed through participation in active measures of public policies on the labor market. Himself coefficient is displayed by the amount of respect persons employed in these measures and were previously unemployed to total unemployed, plus the number of participants in LMP measures that have been unemployed and their unemployment has been interrupted by their participation in these measures. The date of this indicator is shown in Figure 4.

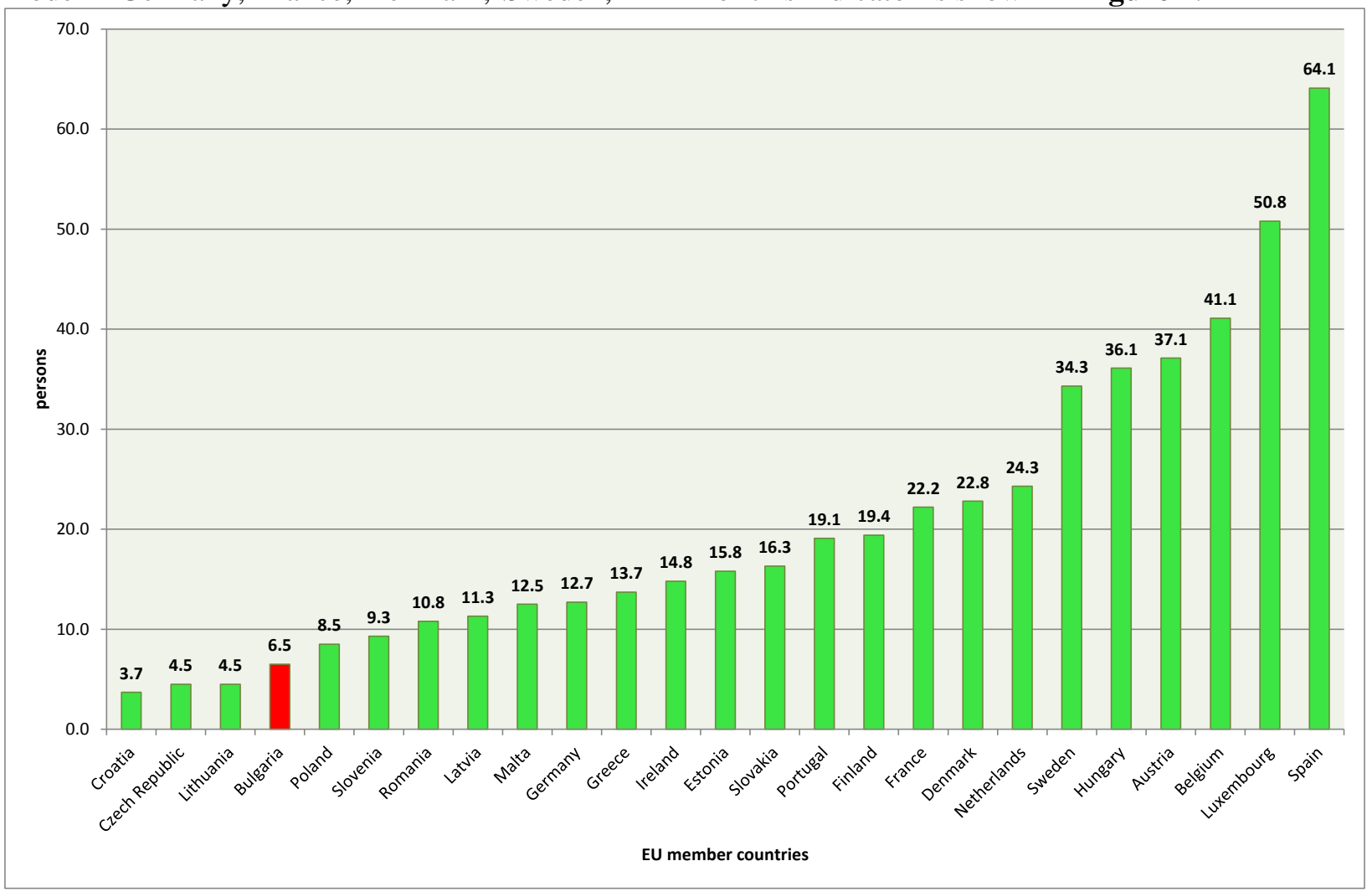

Figure 4. Activation of registered unemployed in 2012.

As can be seen from these data the rate of activation of registered unemployed has a wide scope. Due to lack of data from three Member States - Italy, Cyprus and Britain, missing and average it. But purely arithmetic can be removed average of the other 25 countries and has 20.6. For Bulgaria the value of 6.5 places it on one of the ice-POS locations of all countries. The difference between the activated unemployed for Bulgaria and the EU is over 3 times. Compared to the countries with the highest ratio of activation, Bulgaria lags between 5 and 10 times. This ratio is recognized as one measure of the effectiveness of public policies on the labor market (2). The low value for Bulgaria leads to the conclusion that public policies on the labor market is currently not functioning effectively. If the results are summarized in Figure 3 and Figure 4 can be drawn a general conclusion about 
efficacy issues amongst the programs themselves. Low interest and accordingly low participation of unemployed and willing to work in public policy measures on the labor market in Bulgaria fully corresponds with the low value of the activation of the registered unemployed. So regardless of the volume of the policies of the labor market in Bulgaria can be concluded that they function effectively and even indicate values far below the average for EU member states. Low participation of registered unemployed in the policies of the labor market in Bulgaria can be explained as a consequence of the limited volume of these policies. Under the limited volume should be understood as lower costs allocated to policies on the labor market and limited capacity and interest in innovation that they have.

\section{CONCLUSION}

After the onset of the global crisis in 2008, the labor market of the EU Member States experienced serious problems. The difficulties that ac-company disproportions and imbalances such as increased unemployment and inactivity increase the population appeared in every one of them. In Bulgaria these problems intensified its impact and showed values away from the EU average. Public policies on the labor market as a means to address these problems in the labor market showed an increase in the EU, but in Bulgaria this trend rather marked decline. Lower costs allocated to these policies have led to little interest from unemployed and inactive individuals. As a final result different indices like the activation of registered unemployed showed inefficient functioning of these policies in Bulgaria. Given the dire state of the labor market in Bulgaria should pay more attention to the policies of the labor market as a means of overcoming. Experience, behavior and results in other EU countries should be the goal of increasing the effectiveness of these policies in Bulgaria. Thus establishing an effective tool to minimize the economic and social consequences of the crisis and to help increase economic activity of the national economy.

\section{REFERENCES}

1. Labour market policy statistics : methodology 2013. Luxembourg: Publications Office, 2013. Print

2. Voss, Eckhard, and Antonio Dornelas. "Social partners and flexicurity in contemporary labour markets." Brussels: European Social Partners (2011).

3. Presidency, Belgian. "Active Labour Market Policies for the Europe 2020 Strategy-Ways to move foreward, Antwerp 28-29 October 2010."

4. Kluve, Jochen. "The Effectiveness of European Active Labor Market Policy. IZA DP No. 2018." (2005).

5. Schömann, Klaus. Active labour market policy in the European Union. No. FS I 95201. WZB Discussion Paper, 1995.

6. Dar, Amit, and Zafiris Tzannatos. Active labor market programs: A review of the evidence from evaluations. Social Protection, World Bank, 1999.

7. Calmfors, Lars. "Labour Market Policy and Unemployment." (1994).

8. Card, David, Jochen Kluve, and Andrea Weber. "Active Labour Market Policy Evaluations: A Meta-Analysis*." The Economic Journal 120.548 (2010): F452F477. 